\title{
Parent and Child Screen-Viewing Time and Home Media Environment
}

Russell Jago, Emmanuel Stamatakis, Augusta Gama, Isabel Mourão Carvalhal, Helena Nogueira, Vítor Rosado, Cristina Padez ${ }^{12}$

\section{Abstract}

Background: Screen-viewing time has been associated with adverse health outcomes. Data on the predictors of youth screen-viewing time is predominately from older children in North America. Parental and home media environment factors that are associated with screenviewing time could be targeted in interventions.

Purpose: Examine if parental screen-viewing time and electronic media (access to game equipment, TVs, PCs, and laptops) environment factors were associated with Portuguese children's screen-viewing time and if associations differed by child age ( $<7 \mathrm{vs} \geq 7$ years); gender; or type of screen viewing.

Methods: Data are reported for 2965 families with children aged 3-10 years. Data were collected in 2009-2010 and analyzed in 2011. Outcomes were child spending $\geq 2$ hours watching TV and $\geq 1$ hour per day playing with combined other media. Exposures were mothers and fathers watching $\geq 2$ hours of TV and electronic media variables.

Results: Parental TV-viewing time was strongly associated with child weekday and weekend TV-viewing time across all four gender and age subgroups. Maternal TV-viewing time was a stronger predictor of child TV-viewing time than paternal TV-viewing time. There was very limited evidence that parental TV-viewing time was associated with combined other media time among boys or girls. Access to electronic game equipment increased the likelihood that children spent $>1$ hour using combined other media on weekdays and weekend days.

Conclusions: Parental TV-viewing time was associated with Portuguese children's TV-viewing time. The numbers of TVs in the household and electronic games equipment access were also associated with TV- and combined other media-viewing/usage time.

\footnotetext{
${ }^{1}$ This study was supported by a grant of the Fundação para a Ciência e Tecnologia FCOMP-01-0124FEDER-007483. This paper is also research arising from Career Development Fellowships (to Dr. Jago and Dr. Stamatakis) supported by the UK National Institute for Health Research. The views expressed in this publication are those of the authors and not necessarily those of the NHS, the UK National Institute for Health Research, or the UK Department of Health. No financial disclosures were reported by the authors of this paper.

${ }^{2}$ From the Centre for Exercise, Nutrition and Health Sciences (Jago), School for Policy Studies, University of Bristol, Bristol, Research Department of Epidemiology and Public Health (Stamatakis), Physical Activity Research Group (PARG) (Stamatakis), Research Domain of Population Health, University College London, London, United Kingdom; Faculty of Sciences (Gama), University of Lisbon, Tropical Research Institute (Rosado), Lisbon, Research Centre for Anthropology and Health (Gama, Rosado, Padez), the Department of Geography (Nogueria), the Department of Life Sciences (Padez), University of Coimbra, Coimbra, and the Research Center in Health and Human Development (Carvalhal), University of Tras-os-Montes and Alto Douro, Vila Real, Portugal Address correspondence to: Russell Jago, PhD, Centre for Exercise, Nutrition and Health Sciences, School for Policy Studies, University of Bristol, 8 Priory Rd., Bristol, BS8 1TZ, United Kingdom. E-mail: russ.jago@bris.ac.uk.
} 


\section{Introduction}

Screen-viewing time (TV viewing, playing computer games, and Internet use) has been associated with higher levels of adult obesity, type 2 diabetes, all cause mortality, and cardiovascular events. ${ }^{1,2}$ Among children, screen-viewing time is associated with increased risk of obesity, ${ }^{3-5}$ unhealthy dietary behaviors, ${ }^{6}$ poor mental well-being, and higher levels of cardiovascular risk factors. ${ }^{3,7-10}$ Screen-viewing patterns moderately track from childhood to adulthood, so reducing youth screen-viewing time is important for lifetime disease prevention. ${ }^{11}$

The American Academy of Pediatrics (AAP) ${ }^{12}$ recommends that children's total media time be limited to 1-2 hours of quality programming per day. Data from the National Health and Nutrition Examination Survey (NHANES) ${ }^{13}$ indicated that $33 \%$ of youth exceeded the upper threshold of the AAPTV-viewing guidelines. A number of national bodies have identified reducing youth screen-viewing time as a key public health objective. ${ }^{14-16}$ Behavior change is facilitated by identifying and then modifying the key predictors of the target behavior. ${ }^{17,18} \mathrm{High}$ levels of parental TV viewing were associated with high levels of TV viewing among UK children. ${ }^{19}$ It is important to note, however, that in this sample, data were only collected for one parent and more than $80 \%$ of those parents were mothers. The study therefore does not provide information about whether the association between parent and child screen-viewing time differs by parental gender.

The electronic media environment within the home such as access to media equipment may be important predictors of screen-viewing time. Although access to a TV in the bedroom has been associated with greater TV viewing time among older children and adolescents, the data for young children have been equivocal. ${ }^{20}$ There is also a lack of information about how computer and electronic game access are associated with media time and if associations differ by child age.

Current research on screen-viewing time has been dominated by studies with older children (i.e., age $\geq 10$ years) from North America, Australia, or Northern Europe. ${ }^{20,21}$ Moreover, the majority of the screen-viewing research has focused on weekday TV viewing. The aims of the present study were to examine how maternal and paternal screen-viewing time and electronic media environment factors were associated with screen-viewing time among Portuguese children and if associations differed for weekdays and weekend days, by child age or gender. Specifically, it was hypothesized that (1) parental TV-viewing time is associated with youth screen-viewing time, but associations would differ by parental gender, child age, and day of the week; (2) the home media environment is associated with child screen-viewing time, but associations differ by screen-viewing mode.

\section{Methods}

Data are from the Portuguese Prevalence Study of Obesity in Childhood, which is a cross-sectional study conducted between March 2009 and January 2010. Sampling was based on a proportionate stratified random design that took into account the number of children by age and gender in each district and was designed to provide a nationally representative survey of children aged 7-10 years in Portugal. In each district, schools were randomly selected and 
then year groups were selected within schools. A total of 17,509 children aged 3-10 years provided some data. Participation rate was $57.4 \%$.

There were missing data across all variables. For example, there were 15,038 children with complete weekday TV data, 14,015 fathers with weekend TV data, 12,800 participants who provided data on whether there was a PC in the bedroom, and just 6519 families who reported on the number of pieces of game equipment in the household. In light of the high levels of missing data, analyses were conducted for the 2965 participants who had complete case valid data for all of the weekday or weekend analyses outlined below. The study protocol was approved by Direcção Geral de Inovação e Desenvolvimento Curricular (DGIDC) and parental informed consent was obtained.

\section{Screen-Viewing Variables}

Parents were asked to complete a mailed questionnaire that assessed the screenviewing time of the mother, father, and child who was recruited into the study. Specifically, parents were asked to report the average number of hours per day that the child spent watching TV, using a PC, and playing electronic games on a weekday, Saturday, and Sunday. Response options for all questions were none, $\leq 1$ hour, 1 hour, 2 hours, 3 hours, 4 hours, and $\geq 5$ hours per day.

To obtain a measure of TV-viewing time that was broadly consistent with the AAP guideline, the TV data were recoded into two groups of $<2$ hours per day (none, $\leq 1$ hour, and 1 hour) or $\geq 2$ hours ( 2 hours, 3 hours, 4 hours, or $\geq 5$ hours) per day. Because of the lower frequency of responses, the electronic game and $\mathrm{PC}$ time responses were combined to create a combined other media score variable in which weekday responses of none or $\leq 1$ hour were coded as $\leq 1$ hour per day and all other responses coded as $>1$ hour per day.

To estimate mean weekend TV viewing and combined other media use time, the original categories ( 0 hours, $>1$ hour, 1 hour, 2 hours, 3 hours, 4 hours, $\geq 5$ hours) were recoded into a proxy continuous variable: none was coded as $0, \geq 1$ hour as $0.5,1$ hour as 1,2 hours as 2 , and so on. The scores for Saturday and Sunday were then combined and used to create dichotomous weekend TV-viewing time ( $>2$ vs $\geq 2$ hours per day) and weekend combined other media use time ( $>2$ vs $\geq 2$ hours per day). Parents reported the time that the mother and father spent watching TV on a weekday, Saturday, and Sunday, and the processes outlined above were used to generate dichotomous weekday and weekend TV-viewing time for mothers and fathers separately.

\section{Electronic Media Environment Variables}

Parents reported the number of TVs and the number of pieces of media equipment in the home. Parents also reported whether the child had a TV or PC in their bedroom and if they possessed a laptop computer.

\section{Confounders}

The number of years of maternal and paternal education was reported and collapsed into four groups for each parent ( $\leq 6$ years, 7-9 years, $10-12$ years, and $>12$ years). Height and weight were measured using Seca stadiometer and electronic scale. BMI was calculated and 
classified as healthy weight, overweight, or obese using the International Obesity Task Force (IOTF) guidelines. ${ }^{22}$

\section{Statistical Analysis and Data Handling}

To examine if associations differed by child age, the sample was divided into two agestratified groups of $<7$ or $\geq 7$ years. Descriptive statistics (means, SDs, frequencies, and percentages) were calculated for all variables. Chi-square tests were used to examine if there were any differences in the weekday or weekend TV-viewing behaviors and obesity classification of participants who were included or excluded from the main analyses. The chisquare tests indicated that there is strong evidence $\left(X^{2}=12.54, p<0.001\right)$ of a difference in the percentage of children who watched $>2$ hours of TV on a weekday between the included and excluded ( $27.4 \%$ vs $30.7 \%$ ) sample. There was also evidence that a smaller percentage of participants were classified as obese in the included sample than in the excluded sample $(6.9 \%$ vs $8.4 \%, X^{2=} 9.08, p<0.011$; data not in tabular form). 
Table 1 Descriptive statistics for demographic and media environment variables, $n$ (\%) unless otherwise noted

\begin{tabular}{|c|c|c|}
\hline & Boys & Girls \\
\hline \multirow{2}{*}{$\begin{array}{l}\text { Number of pieces of } \\
\text { game equipment } \\
\text { in home }(n, \\
M[S D])^{\mathrm{a}}\end{array}$} & 1426 & 1539 \\
\hline & $0.97(0.86)$ & $0.67(0.80)$ \\
\hline \multicolumn{3}{|l|}{ CHILD } \\
\hline \multicolumn{3}{|l|}{ Age (years) } \\
\hline$<7$ & $710(49.8)$ & $738(47.9)$ \\
\hline$\geq 7$ & $716(50.2)$ & $801(52.1)$ \\
\hline \multicolumn{3}{|l|}{ Weekday TV time } \\
\hline$<2$ & $1024(71.8)$ & $1130(73.4)$ \\
\hline$\geq 2$ & $402(28.2)$ & $409(26.6)$ \\
\hline \multicolumn{3}{|c|}{ Average weekend TV time } \\
\hline$<2$ & $348(24.4)$ & $394(25.6)$ \\
\hline$\geq 2$ & $1078(75.6)$ & $1145(74.4)$ \\
\hline \multicolumn{3}{|c|}{ Weekday combined other media usage time } \\
\hline$<1$ & $1092(76.6)$ & $1318(85.6)$ \\
\hline$\geq 1$ & $334(23.4)$ & $221(14.4)$ \\
\hline \multicolumn{3}{|c|}{ Weekend combined other media usage time } \\
\hline$<1$ & $535(37.5)$ & $692(45.0)$ \\
\hline$\geq 1$ & $891(62.5)$ & $847(55.0)$ \\
\hline \multicolumn{3}{|l|}{ FATHER } \\
\hline \multicolumn{3}{|l|}{ Weekday TV time } \\
\hline$<2$ & $1217(85.5)$ & $1313(85.5)$ \\
\hline$\geq 2$ & 207 (14.5) & $222(14.5)$ \\
\hline \multicolumn{3}{|l|}{ Weekend TV time } \\
\hline$<2$ & $887(62.2)$ & $943(61.3)$ \\
\hline$\geq 2$ & $539(37.8)$ & $596(38.7)$ \\
\hline \multicolumn{3}{|l|}{ MOTHER } \\
\hline \multicolumn{3}{|l|}{ Weekday TV time } \\
\hline$<2$ & $1306(91.7)$ & $1427(93.1)$ \\
\hline$\geq 2$ & $118(8.3)$ & $106(6.9)$ \\
\hline \multicolumn{3}{|l|}{ Weekend TV time } \\
\hline$<2$ & $1099(77.1)$ & $1175(76.4)$ \\
\hline$\geq 2$ & $327(22.9)$ & $364(23.7)$ \\
\hline \multicolumn{3}{|l|}{ IOTF classification } \\
\hline Healthy weight & $1067(74.8)$ & $1078(70.1)$ \\
\hline Overweight & $264(18.5)$ & $352(22.9)$ \\
\hline Obese & $95(6.7)$ & $109(7.1)$ \\
\hline & & (continued) \\
\hline
\end{tabular}

Table 1 (continued)

\begin{tabular}{|c|c|c|}
\hline & Boys & Girls \\
\hline \multicolumn{3}{|c|}{ Number of TVs in home } \\
\hline$\leq 1$ & $184(12.9)$ & $228(14.8)$ \\
\hline $2-3$ & $893(62.6)$ & $927(60.2)$ \\
\hline$\geq 4$ & $349(24.5)$ & $384(25.0)$ \\
\hline \multicolumn{3}{|c|}{ Equipment in home, $n$ (response) } \\
\hline $\begin{array}{l}\text { TV in child's } \\
\text { bedroom (yes) }\end{array}$ & $576(48.3)$ & $616(51.7)$ \\
\hline Laptop (yes) & $279(42.5)$ & $378(57.5)$ \\
\hline $\begin{array}{l}\mathrm{PC} \text { in bedroom } \\
\text { (yes) }\end{array}$ & $144(50.7)$ & $140(49.3)$ \\
\hline
\end{tabular}

Note: Boldface indicates significance. Time is given in hours per day. "Data presented are the number of boys or girls with game equipment in the home, followed by M (SD).

IOTF, International Obesity Task Force; PC, personal computer

Logistic regression models were used to examine whether maternal, paternal, or electronic media environment variables predicted whether the child spent $>2$ hours per day watching TV on a weekday or weekend day. All models were run stratified by gender and age group and were mutually adjusted for all variables along with maternal and paternal education and IOTF BMI group. Analogous models were run to assess the association between the above independent variables and weekday or weekend combined other media time $(<1$ hour/day vs $>1$ hour/day). Robust SEs, which use residuals at the cluster level to account for similarity of individuals within clusters (schools), were used to account for the clustering of children within schools in the $p$-values and $95 \% \mathrm{Cls}^{23}$ 
In light of the number of different analyses conducted, an arbitrary alpha value was not set, but rather analyses were interpreted in light of the strength of evidence of associations, with $p$-values of 0.05 interpreted as some evidence against the null hypothesis, $p=0.01$ was interpreted as increasing evidence against the null hypothesis, and $p=0.001$ was interpreted as strong evidence against the null hypothesis. ${ }^{24}$ Analyses were performed in Stata, version 10.0.

\section{Results}

Descriptive statistics, stratified by child gender, are presented in Table 1 . The sample was composed of $1448(48.8 \%)$ children aged < 7 years and 1517 children aged $7-10$ years $(51.2 \%)$, with $51.2 \%$ of the sample being girls. Around $28 \%$ of boys and $26 \%$ of girls watched $>$ 2 hours of TV on a weekday, with this figure rising to $75 \%$ and $74 \%$ on the weekend. For weekdays, $14 \%$ of fathers and $8 \%$ of mothers watched $>2$ hours of TV per day, with these figures rising to $38 \%$ of fathers and $23 \%$ of mothers for weekends. Around $50 \%$ of children had a TV in their bedroom, with similar numbers for a PC. In terms of paternal education, 587 $(19.8 \%)$ fathers had $<6$ years of education; 885 (29.9\%) had $7-9$ years; $574(19.4 \%)$ had $10-12$ years; and 919 (31.0) had > 12 years. Similarly, 349 mothers (11.8\%) had < 6 years of education; 680 (22.9\%) had 7-9 years; 657 (22.2\%) had $10-12$ years; and 1279 (43.1\%) had > 12 years (data not in tabular form).

The logistic regression models predicting whether children watched $\geq 2$ hours of TV per weekday are presented in Table 2. There was increasing to strong evidence that children who had mothers and fathers who watched $>2$ hours of TV per day were also more likely to watch $>2$ hours of TV per day, with the ORs ranging from $2.05(p=0.008)$ for paternal TV-viewing time predicting TV-viewing time for girls aged $\geq 7$ years to $7.94(p=0.001)$ for maternal TVviewing time. There was also increasing evidence that a TV in the child's bedroom was associated with increased odds of girls aged $\geq 7$ years watching $>2$ hours of TV per day (OR= $1.91, p=0.002$ ). Comparable patterns were also evident for weekend TV-viewing time (Table 3). 
Table 2. Logistic regression with child weekday TV-viewing time predicted by parental TV-viewing time and media environment variables ${ }^{a}$

\begin{tabular}{|c|c|c|c|c|c|c|}
\hline & \multicolumn{3}{|c|}{ Boys } & \multicolumn{3}{|c|}{ Girls } \\
\hline & OR $(95 \% \mathrm{Cl})$ & $z$ & $p$ & OR $(95 \% \mathrm{Cl})$ & $z$ & $p$ \\
\hline \multicolumn{7}{|l|}{ AGED $<7$ YEARS } \\
\hline $\begin{array}{l}\text { Paternal TV-viewing time }>2 \text { hours per day } \\
\quad(\text { ref }<2 \text { hours) }\end{array}$ & $2.66(1.78,3.99)$ & 4.76 & $<0.001$ & $2.05(1.20,3.50)$ & 2.64 & 0.008 \\
\hline $\begin{array}{l}\text { Maternal TV-viewing time }>2 \text { hours per day } \\
\quad(\text { ref }<2 \text { hours) }\end{array}$ & $3.28(1.88,5.75)$ & 4.16 & $<0.001$ & $7.94(3.56,17.68)$ & 5.07 & $<0.001$ \\
\hline \multicolumn{7}{|l|}{ Number of TVs in household (ref $\leq \mathbf{1}$ ) } \\
\hline $2-3$ & $1.05(0.54,2.03)$ & 0.16 & 0.877 & $1.24(0.72,2.12)$ & 0.78 & 0.437 \\
\hline$\geq 4$ & $0.99(0.45,2.19)$ & -0.01 & 0.991 & $1.20(0.50,2.90)$ & 0.41 & 0.682 \\
\hline TV in child's bedroom & $1.14(0.79,1.66)$ & 0.70 & 0.484 & $1.45(0.92,2.31)$ & 1.58 & 0.113 \\
\hline $\mathrm{PC}$ in bedroom & $0.83(0.42,1.62)$ & -0.55 & 0.584 & $0.57(0.30,1.08)$ & -1.74 & 0.083 \\
\hline Laptop & $0.60(0.26,1.36)$ & -1.22 & 0.221 & $0.97(0.62,1.52)$ & -0.14 & 0.891 \\
\hline Number of pieces of game equipment in home & $1.16(0.90,1.38)$ & 1.00 & 0.317 & $1.06(0.85,1.33)$ & 0.50 & 0.614 \\
\hline \multicolumn{7}{|l|}{ AGED $\geq 7$ YEARS } \\
\hline $\begin{array}{l}\text { Paternal TV-viewing time }>2 \text { hours per day } \\
\quad \text { (ref }<2 \text { hours) }\end{array}$ & $2.44(1.52,3.90)$ & 3.72 & $<0.001$ & $2.32(1.38,3.89)$ & 3.19 & 0.001 \\
\hline $\begin{array}{l}\text { Maternal TV-viewing time }>2 \text { hours per day } \\
\quad(\text { ref }<2 \text { hours) }\end{array}$ & $3.94(2.00,7.73)$ & 3.97 & $<0.001$ & $2.84(1.40,5.74)$ & 2.91 & 0.004 \\
\hline \multicolumn{7}{|l|}{ Number of TVs in household (ref $\leq 1$ ) } \\
\hline $2-3$ & $1.16(0.63,2.13)$ & 0.48 & 0.634 & $0.83(0.56,1.21)$ & -0.97 & 0.333 \\
\hline$\geq 4$ & $0.89(0.44,1.79)$ & -0.33 & 0.742 & $0.67(0.40,1.12)$ & -1.53 & 0.216 \\
\hline TV in child's bedroom & $1.12(0.80,1.57)$ & 0.68 & 0.496 & $1.91(1.26,2.90)$ & 3.06 & 0.002 \\
\hline $\mathrm{PC}$ in bedroom & $0.81(0.38,1.72)$ & -0.54 & 0.586 & $1.18(0.76,1.85)$ & 0.74 & 0.457 \\
\hline Laptop & $1.35(0.81,2.24)$ & 1.14 & 0.253 & $1.12(0.80,1.58)$ & 0.67 & 0.500 \\
\hline Number of pieces of game equipment in home & $1.28(0.97,1.70)$ & 1.74 & 0.082 & $0.92(0.75,1.10)$ & -0.93 & 0.351 \\
\hline
\end{tabular}

Note: For boys aged $<7$ years, $n=708$; for girls aged $<7$ years, $n=733$; for boys aged $\geq 7$ years, $n=714$; for girls aged $\geq 7$ years, $n=797$. ${ }^{a}$ Models are mutually adjusted for all variables as well as maternal and paternal education, child BMl group, and the clustering of children in schools.

$\mathrm{PC}$, personal computer 
Table 3. Logistic regression with child weekend TV-viewing time predicted by parental TV-viewing time and media environment variables ${ }^{a}$

\begin{tabular}{|c|c|c|c|c|c|c|}
\hline & \multicolumn{3}{|c|}{ Boys } & \multicolumn{3}{|c|}{ Girls } \\
\hline & $\mathrm{OR}(95 \% \mathrm{Cl})$ & $z$ & $p$ & OR (95\% Cl) & $z$ & $p$ \\
\hline \multicolumn{7}{|l|}{ AGED $<7$ YEARS } \\
\hline $\begin{array}{l}\text { Paternal TV-viewing time }>2 \text { hours per day } \\
\quad \text { (ref }<2 \text { hours) }\end{array}$ & $1.78(1.15,2.78)$ & 2.56 & 0.010 & $1.49(1.13,1.96)$ & 2.82 & 0.005 \\
\hline $\begin{array}{l}\text { Maternal TV-viewing time }>2 \text { hours per day } \\
\quad \text { (ref }<2 \text { hours) }\end{array}$ & $3.66(2.09,6.41)$ & 4.53 & $<0.001$ & $2.99(1.86,4.80)$ & 4.52 & $<0.001$ \\
\hline \multicolumn{7}{|l|}{ Number of TVs in household (ref $\leq 1$ ) } \\
\hline $2-3$ & $1.19(0.79,1.80)$ & 0.83 & 0.409 & $0.99(0.66,1.49)$ & -0.03 & 0.977 \\
\hline$\geq 4$ & $1.04(0.61,1.78)$ & 0.14 & 0.886 & $1.19(0.72,1.97)$ & 0.69 & 0.488 \\
\hline TV in child's bedroom & $1.34(0.93,1.94)$ & 1.57 & 0.117 & $1.32(0.93,1.87)$ & 1.54 & 0.123 \\
\hline PC in bedroom & $1.80(0.94,3.42)$ & 1.78 & 0.075 & $1.47(0.66,3.30)$ & 0.94 & 0.348 \\
\hline Laptop & $0.66(0.62,1.37)$ & -1.12 & 0.264 & $1.57(1.02,2.44)$ & 2.03 & 0.042 \\
\hline Number of pieces of game equipment in home & $1.44(1.11,1.87)$ & 2.71 & 0.007 & $1.14(0.97,1.33)$ & 1.63 & 0.103 \\
\hline \multicolumn{7}{|l|}{ AGED $\geq 7$ YEARS } \\
\hline $\begin{array}{l}\text { Paternal TV-viewing time }>2 \text { hours per day } \\
\text { (ref }<2 \text { hours) }\end{array}$ & $1.75(1.23,2.47)$ & 3.11 & 0.002 & $1.57(1.03,2.39)$ & 2.09 & 0.037 \\
\hline $\begin{array}{l}\text { Maternal TV-viewing time }>2 \text { hours per day } \\
\quad \text { (ref }<2 \text { hours) }\end{array}$ & $4.45(1.89,10.45)$ & 3.42 & 0.001 & $2.32(1.42,3.80)$ & 3.37 & 0.001 \\
\hline \multicolumn{7}{|l|}{ Number of TVs in household (ref $\leq 1$ ) } \\
\hline $2-3$ & $0.74(0.45,1.21)$ & -1.20 & 0.231 & $0.97(0.55,1.72)$ & -0.09 & 0.926 \\
\hline$\geq 4$ & $1.04(0.52,2.06)$ & 0.10 & 0.922 & $1.20(0.58,2.50)$ & 0.50 & 0.619 \\
\hline TV in child's bedroom & $0.94(0.49,1.76)$ & -0.22 & 0.825 & $1.26(0.68,2.33)$ & 0.75 & 0.455 \\
\hline PC in bedroom & $1.40(0.65,3.04)$ & 0.86 & 0.392 & $1.35(0.61,3.00)$ & 0.73 & 0.464 \\
\hline Laptop & $0.86(0.55,1.34)$ & -0.68 & 0.498 & $1.25(0.80,1.97)$ & 0.97 & 0.330 \\
\hline Number of pieces of game equipment in home & $1.06(0.84,1.34)$ & 0.49 & 0.624 & $0.95(0.77,1.17)$ & -0.49 & 0.626 \\
\hline
\end{tabular}

Note: For boys aged $<7$ years, $n=710$; for girls aged $<7$ years, $n=738$; for boys aged $\geq 7$ years, $n=716$; for girls aged $\geq 7$ years, $n=801$ ${ }^{\mathrm{a}}$ Models are mutually adjusted for all variables as well as maternal and paternal education, child BMI group, and the clustering of children in schools.

$\mathrm{PC}$, personal computer

The logistic regression models predicting whether participants spent $>1$ hour using combined other media on a weekday is presented stratified by gender and age group in Table 4. There was increasing evidence that high paternal TV-viewing time was associated with higher levels of combined other media usage time among boys aged $<7$ years $(\mathrm{OR}=2.01, p=$ 0.003 ). Among all age and gender groups, there was strong evidence that the number of pieces of electronic game equipment was associated with increased odds that the child spent $>1$ hour per day using combined other media.

Among younger boys, there was strong evidence that having a PC in the bedroom was associated with an increased likelihood that the child spent 1 hour per day using combined other media ( $O R=2.70, p=0.001)$. There was strong evidence that having a TV in the bedroom was associated with increased likelihood of older boys spending $>1$ hour per day using combined other media $(O R=2.15, p=0.001)$. There was also increasing evidence that having a laptop was associated with an increased likelihood that younger $(\mathrm{OR}=3.40, p=0.005)$ and older girls (OR=1.96, $p=0.001)$ spent $>1$ hour per day using combined other media.

The logistic regression models predicting weekend combined other media usage time are presented in Table 5. There was increasing evidence that higher paternal TV-viewing time was associated with an increased likelihood that older girls spent $>1$ hour per day using 
combined other media $(\mathrm{OR}=1.63, p=0.003)$. There was strong evidence $(p<0.001)$ that the number of pieces of electronic game equipment in the home was associated with an increased likelihood of spending $>1$ hour per day using combined other media in all four age and gender groups, with the ORs ranging from 1.85 for older girls to 4.65 for young boys. There was also strong evidence $(p<0.001)$ that having a laptop computer was associated with an increased likelihood of both younger boys $(O R=4.26)$ and younger girls $(O R=2.71)$ spending $>1$ hour per day using combined other media.

Table 4. Logistic regression with child weekday other media time predicted by parental TV and media environment variables ${ }^{a}$

\begin{tabular}{|c|c|c|c|c|c|c|}
\hline & \multicolumn{3}{|c|}{ Boys } & \multicolumn{3}{|c|}{ Girls } \\
\hline & OR $(95 \% \mathrm{Cl})$ & $z$ & $p$ & OR $(95 \% \mathrm{Cl})$ & $z$ & $p$ \\
\hline \multicolumn{7}{|l|}{ AGED $<7$ YEARS } \\
\hline $\begin{array}{l}\text { Paternal TV-viewing time }>2 \text { hours per day } \\
\quad(\text { ref }<2 \text { hours) }\end{array}$ & $2.01(1.27,3.18)$ & 2.97 & 0.003 & $1.08(0.51,2.31)$ & 0.19 & 0.848 \\
\hline $\begin{array}{l}\text { Maternal TV-viewing time }>2 \text { hours per day } \\
\quad(\text { ref }<2 \text { hours) }\end{array}$ & $0.33(0.09,1.12)$ & -1.78 & 0.075 & $2.21(0.77,6.31)$ & 1.48 & 0.140 \\
\hline \multicolumn{7}{|l|}{ Number of TVs in household (ref $\leq 1$ ) } \\
\hline $2-3$ & $1.48(0.56,3.97)$ & 0.79 & 0.430 & $1.04(0.47,2.33)$ & 0.10 & 0.919 \\
\hline$\geq 4$ & $1.37(0.43,4.34)$ & 0.54 & 0.588 & $0.62(0.19,2.00)$ & -0.80 & 0.423 \\
\hline TV in child's bedroom & $0.88(0.39,1.97)$ & -0.32 & 0.750 & $0.99(0.59,1.64)$ & -0.05 & 0.963 \\
\hline $\mathrm{PC}$ in bedroom & $2.70(1.52,4.81)$ & 3.38 & 0.001 & $1.20(0.40,3.60)$ & 0.32 & 0.745 \\
\hline Laptop & $1.71(0.77,3.79)$ & 1.31 & 0.189 & $3.40(1.45,8.04)$ & 2.80 & 0.005 \\
\hline Number of pieces of games equipment in home & $3.43(2.60,4.53)$ & 8.70 & $<0.001$ & $2.94(2.06,4.18)$ & 5.96 & $<0.001$ \\
\hline \multicolumn{7}{|l|}{ AGED $\geq 7$ YEARS } \\
\hline $\begin{array}{l}\text { Paternal TV-viewing time }>2 \text { hours per day } \\
\quad(\text { ref }<2 \text { hours) }\end{array}$ & $1.26(0.74,2.14)$ & 0.86 & 0.389 & $0.96(0.54,1.70)$ & -0.15 & 0.878 \\
\hline $\begin{array}{l}\text { Maternal TV-viewing time }>2 \text { hours per day } \\
\quad(\text { ref }<2 \text { hours) }\end{array}$ & $2.23(0.91,5.50)$ & 1.75 & 0.081 & $2.12(0.92,4.90)$ & 1.76 & 0.079 \\
\hline \multicolumn{7}{|l|}{ Number of TVs in household (ref $\leq 1$ ) } \\
\hline $2-3$ & $0.58(0.36,0.94)$ & -2.24 & 0.025 & $0.96(0.63,1.46)$ & -0.18 & 0.855 \\
\hline$\geq 4$ & $0.90(0.30,1.14)$ & -1.58 & 0.114 & $0.77(0.40,1.51)$ & -0.76 & 0.448 \\
\hline TV in child's bedroom & $2.15(1.59,2.92)$ & 4.95 & $<0.001$ & $0.96(0.69,1.33)$ & -0.26 & 0.797 \\
\hline $\mathrm{PC}$ in bedroom & $1.44(0.95,2.18)$ & 1.71 & 0.087 & $1.75(1.09,2.80)$ & 2.32 & 0.020 \\
\hline Laptop & $1.08(0.85,1.37)$ & 0.63 & 0.528 & $1.96(1.30,2.97)$ & 3.21 & 0.001 \\
\hline Number of pieces of game equipment in home & $1.57(1.30,1.89)$ & 4.70 & $<0.001$ & $1.60(1.31,1.94)$ & 4.67 & $<0.001$ \\
\hline
\end{tabular}

Note: For boys aged $<7$ years, $n=708$; for girls aged $<7$ years, $n=733$; for boys aged $\geq 7$ years, $n=714$; for girls aged $\geq 7$ years, $n=797$ ${ }^{\mathrm{a}}$ Models are mutually adjusted for all variables as well as maternal and paternal education, child BMl group, and the clustering of children in schools.

$\mathrm{PC}$, personal computer

\section{Discussion}

In this Portuguese study, parental TV-viewing time was strongly associated with young children's TV-viewing time, with patterns broadly comparable for boys and girls. Children who lived in a home where the parent watched more than 2 hours of TV per day were between 1.5 and 8 times more likely to also watch more than 2 hours of TV per day. Maternal TV viewing was a stronger predictor of child TV viewing than paternal TV viewing on both weekdays and weekend days for all age and gender subgroups. This finding might indicate that in Portugal mothers have a particularly important role in modeling screen-viewing behaviors and as such working with mothers to reduce family screen-viewing time may be important.

Data are consistent with those of a study in the United Kingdom ${ }^{19}$ which showed that for both boys and girls, the risk of watching more than 4 hours of TV was greater if the parent 
watched more than 2 hours of TV per day. Collectively, these findings indicate that there is a need for family interventions that aim to reduce the TV-viewing time of parents and children together. Moreover, reducing TV-viewing time on weekdays when perhaps time for other activities is limited because of school and homework may be advantageous. The bulk of current interventions have focused on reducing TV-viewing time via school-based educational components in which parental involvement is limited to interaction with homework. ${ }^{25,26}$ The data presented here suggest that there is a need to build on these efforts by developing family-based interventions with parents and children working together to change family screen-viewing behaviors.

Table 5. Logistic regression with child weekend other media time predicted by parental TV and media environment variables ${ }^{\mathrm{a}}$

\begin{tabular}{|c|c|c|c|c|c|c|}
\hline & \multicolumn{3}{|c|}{ Boys } & \multicolumn{3}{|c|}{ Girls } \\
\hline & $\mathrm{OR}(95 \% \mathrm{Cl})$ & $z$ & $p$ & $\mathrm{OR}(95 \% \mathrm{Cl})$ & $z$ & $p$ \\
\hline \multicolumn{7}{|l|}{ AGED $<7$ YEARS } \\
\hline $\begin{array}{l}\text { Paternal TV-viewing time }>2 \text { hours per day } \\
\text { (ref }<2 \text { hours) }\end{array}$ & $1.34(0.97,1.84)$ & 1.80 & 0.073 & $1.35(0.99,1.83)$ & 1.94 & 0.053 \\
\hline $\begin{array}{l}\text { Maternal TV-viewing time }>2 \text { hours per day } \\
\quad \text { (ref }<2 \text { hours) }\end{array}$ & $1.12(0.73,1.73)$ & 0.50 & 0.615 & $0.98(0.67,1.45)$ & -0.08 & 0.932 \\
\hline \multicolumn{7}{|l|}{ Number of TVs in household (ref $\leq \mathbf{1}$ ) } \\
\hline $2-3$ & $1.62(1.00,2.60)$ & 1.97 & 0.049 & $1.06(0.74,1.52)$ & 0.32 & 0.746 \\
\hline$\geq 4$ & $2.00(1.13,3.54)$ & 2.39 & 0.017 & $1.10(0.73,1.68)$ & 0.45 & 0.650 \\
\hline TV in child's bedroom & $0.73(0.44,1.20)$ & -1.25 & 0.210 & $1.12(0.83,1.52)$ & 0.75 & 0.455 \\
\hline $\mathrm{PC}$ in bedroom & $1.50(0.78,2.90)$ & 1.21 & 0.225 & $1.33(0.61,2.87)$ & 0.72 & 0.472 \\
\hline Laptop & $4.26(1.82,9.99)$ & 3.33 & 0.001 & $2.71(1.67,4.40)$ & 4.04 & $<0.001$ \\
\hline Number of pieces of game equipment in home & $4.65(3.58,6.03)$ & 11.58 & $<0.001$ & $1.99(1.57,2.54)$ & 5.59 & $<0.001$ \\
\hline \multicolumn{7}{|l|}{ AGED $\geq 7$ YEARS } \\
\hline $\begin{array}{l}\text { Paternal TV-viewing time }>2 \text { hours per day } \\
\quad(\text { ref }<2 \text { hours) }\end{array}$ & $1.45(0.92,2.28)$ & 1.60 & 0.109 & $1.63(1.18,2.25)$ & 2.97 & 0.003 \\
\hline $\begin{array}{l}\text { Maternal TV-viewing time }>2 \text { hours per day } \\
\quad(\text { ref }<2 \text { hours) }\end{array}$ & $1.43(0.76,2.65)$ & 1.12 & 0.264 & $0.98(0.60,1.62)$ & -0.06 & 0.950 \\
\hline \multicolumn{7}{|l|}{ Number of TVs in household (ref $\leq 1$ ) } \\
\hline $2-3$ & $1.63(0.92,2.89)$ & 1.66 & 0.096 & $1.04(0.71,1.54)$ & 0.22 & 0.825 \\
\hline$\geq 4$ & $1.46(0.52,4.09)$ & 0.72 & 0.470 & $1.17(0.72,1.90)$ & 0.65 & 0.515 \\
\hline TV in child's bedroom & $1.54(0.95,2.47)$ & 1.76 & 0.078 & $1.16(0.87,1.55)$ & 0.99 & 0.321 \\
\hline PC in bedroom & $1.82(1.08,3.07)$ & 2.25 & 0.025 & $2.38(1.29,4.62)$ & 2.57 & 0.010 \\
\hline Laptop & $0.75(0.48,1.17)$ & -1.28 & 0.202 & $1.15(0.77,1.69)$ & 0.68 & 0.498 \\
\hline Number of pieces of game equipment in home & $3.69(2.31,5.90)$ & 5.46 & $<0.001$ & $1.85(1.51,2.26)$ & 6.03 & $<0.001$ \\
\hline
\end{tabular}

Note: For boys aged $<7$ years, $n=710$; for girls aged $<7$ years, $n=738$; for boys aged $\geq 7$ years, $n=716$; for girls aged $\geq 7$ years, $n=801$. ${ }^{a}$ Models are mutually adjusted for all variables as well as maternal and paternal education, child BMI group, and the clustering of children in schools.

There was limited evidence that parental TV-viewing patterns were associated with combined other media use but access to media equipment is a key factor, with associations differing by age and gender. Among all four subgroups, there was strong evidence that having increased access to electronic game equipment increased the likelihood that the children spent more than 1 hour using combined other media on both weekdays and weekend days. Collectively, these findings indicate that increased access to media equipment, particularly among younger children, is associated with an increased likelihood that the participants would have high levels of screen-viewing time. Findings are consistent with previous studies conducted with older children and adolescents in Northern Europe, Australia, and the U.S. and 
indicate that young Portuguese children who live in homes with greater access to electronic media equipment engage in higher levels of screen viewing. ${ }^{27-29}$

The data presented in this paper suggest that family based strategies to reduce screenviewing time could include approaches to limiting access to electronic media equipment during defined periods across the day. Support for this hypothesis is provided by Epstein and colleagues' work which showed that an automated TV allowance device that children and all members of a family can use to set TV-viewing reduction goals can help attain reductions in child TV viewing. ${ }^{30}$ As the Epstein study was conducted with children whose BMI were at the 75th percentile or higher, there is a need to examine if this approach would work with lessoverweight children. Moreover, there is also a need to identify if interventions that do not require an automated device can be developed for use with contemporary portable devices such as tablet computers and smart-phones.

\section{Strengths and Limitations}

This is the first large study to report on the associations between parent and child screen-viewing time among Portuguese families with young children. The study also provides new information about the associations between maternal and paternal viewing on children's behavior and how associations differ by weekday vs weekend day and child age. It is important to recognize that the current analyses included only a subgroup of participants from a much larger sample. There was some evidence that the included participants were slightly less overweight and slightly less likely to watch more than 2 hours of TV on a weekday than the excluded participants. Thus, although the sample is large and provides important information about a topic in an understudied group, it is not possible to claim that the analyzed sample is representative of children aged $7-10$ years in Portugal.

The study is limited by the use of parental proxy reports of children's behavior. Moreover, as the current study provides assessments of only TV-viewing and combined other media time per day, it is not possible to differentiate when during the day viewing occurred. It is also important to highlight that as the questions were asked about each behavior separately, it is unknown to what extent children or parents may have been engaging in multiscreen viewing whereby they might be using a laptop computer while also watching TV. ${ }^{31}$

As the questionnaire was self-completed at home, it is possible that one parent might have answered all of the questions for both parents which could have introduced a degree of error into the results. It is also important to highlight that parental education provides information on only one dimension of SES. Finally, as the presented data are from a crosssectional survey, it is not possible to infer casual associations between variables.

\section{Conclusion}

In this study in Portugal, parental TV-viewing time, particularly on the part of mothers, was associated with young children's TV-viewing time, but there was limited evidence that parental TV-viewing time was associated with children's combined other media usage time. The home electronic media environment, such as the number of TVs in the household and access to electronic game equipment, was also associated with children's TV-viewing and combined other media usage time. 


\section{References}

1. Stamatakis E, Hamer M, Dunstan DW. Screen-based entertainment time, all-cause mortality, and cardiovascular events: population-based study with ongoing mortality and hospital events follow-up. J Am Coll Cardiol 2011; 57(3):292-9.

2. Grontved A, Hu FB. Television viewing and risk of type 2 diabetes, cardiovascular disease, and all-cause mortality: a meta-analysis. JAMA 2011; 305(23):2448 -55.

3. Jago R, Baranowski T, Baranowski JC, Thompson D, Greaves KA. BMI from 3-6 y of age is predicted by TV viewing and physical activity, not diet. Int J Obes Relat Metab Disord 2005; 29(6):557-64.

4. Padez C, Mourao I, Moreira P, Rosado V. Prevalence and risk factors for overweight and obesity in Portuguese children. Acta Paediatr 2005; 94(11):1550 -7.

5. Carvalhal MM, Padez MC, Moreira PA, Rosado VM. Overweight and obesity related to activities in Portuguese children, 7-9 years. Eur J Public Health 2007;17(1):42-6.

6. Pearson N, Biddle SJH. Sedentary behavior and dietary intake in children, adolescents, and adults: a systematic review. Am J Prev Med 2011; 41(2):178-88.

7. Marshall SJ, Biddle SJH, Gorley T, Camerron N, Murdey I. Relationships between media use, body fatness and physical activity in children and youth: a meta-analysis. Int J Obes Relat Metab Disord 2004; 28: 1238-46.

8. Ekelund U, Brage S, Froberg K, et al. TV viewing and physical activity are independently associated with metabolic risk in children: the European Youth Heart Study. PLoS Med 2006; 3(12):e488.

9. Page AS, Cooper AR, Griew P, Jago R. Children's screen viewing is related to psychological difficulties irrespective of physical activity. Pediatrics 2010; 126(5):e1011- e1017.

10. Hamer M, Stamatakis E, Mishra G. Psychological distress, television viewing, and physical activity in children aged 4 to 12 years. Pediatrics 2009; 123(5):1263-8.

11. Biddle SJ, Pearson N, Ross GM, Braithwaite R. Tracking of sedentary behaviours of young people: a systematic review. Prev Med 2010; 51(5):345-51.

12. American Academy of Pediatrics-Committee on Public Education. Children, adolescents, and television. Pediatrics 2001; 107(2):423-6.

13. Sisson SB, Church TS, Martin CK, et al. Profiles of sedentary behavior in children and adolescents: the US National Health and Nutrition Examination Survey, 2001-2006. Int J Pediatr Obes 2009; 4(4):353-9.

14. Tremblay MS, Leblanc AG, Janssen I, et al. Canadian sedentary behavior guidelines for children and youth. Appl Physiol Nutr Metab 2011; 36(1):59-64.

15. Department of Health. Change 4 Life. In: www.nhs.uk/change4life/Pages/Default.aspx.

16. Salmon J, Tremblay MS, Marshall SJ, Hume C. Health risks, correlates, and interventions to reduce sedentary behavior in young people. Am J Prev Med 2011; 41(2):197-206. 
17. Craig P, Dieppe $P$, Macintyre $S$, Michie $S$, Nazareth I, Petticrew M. Developing and evaluating complex interventions: the new Medical Research Council guidance. BMJ 2008; 337:a1655.

18. Baranowski T, Jago R. Understanding mechanisms of change in children's physical activity programs. Exerc Sport Sci Rev 2005; 33(4):163-8.

19. Jago R, Fox KR, Page AS, Brockman R, Thompson JL. Parent and child physical activity and sedentary time: do active parents foster active children? BMC Public Health 2010; 10(1):194.

20. Hoyos Cillero I, Jago R. Systematic review of correlates of screenviewing among young children. Prev Med 2010; 51(1):3-10.

21. Gorely T, Marshall SJ, Biddle SJ. Couch kids: correlates of television viewing among youth. Int J Behav Med 2004; 11(3):152-63.

22. Cole TJ, Bellizzi MC, Flegal KM, Dietz WH. Establishing a standard definition for child overweight and obesity worldwide: international survey. BMJ 2000; 320(7244):1240 -3.

23. Kirkwood BR, Sterne AC. Essential medical statistics. London: Blackwell, 2006.

24. Sterne JA, Davey Smith G. Sifting the evidence - what's wrong with significance tests? BMJ $2001 ; 322(7280): 226-31$.

25. Robinson TN. Reducing children's television viewing to prevent obesity - a randomized controlled trial. JAMA 1999; 282(16):1561-7.

26. Kipping R, Payne C, Lawlor DA. Randomised controlled trial adapting American school obesity prevention to England. Arch Dis Child 2008; 93(6):469 -73.

27. Jago R, Page A, Froberg K, Sardinha LB, Klasson-Heggebo L, Andersen LB. Screen-viewing and the home TV environment: the European Youth Heart Study. Prev Med 2008; 47(5):525-9.

28. Saelens BE, Sallis JF, Nader PR, Broyles SL, Berry CC, Taras HL. Home environmental influences on children's television watching from early to middle childhood. J Dev Behav Pediatr 2002; 23(3): 127-32.

29. Hardy LL, Baur LA, Garnett SP, et al. Family and home correlates of television viewing in 12 13 year old adolescents: the Nepean Study. Int J Behav Nutr Phys Act 2006;3:24.

30. Epstein LH, Roemmich JN, Robinson JL, et al. Arandomized trial of the effects of reducing television viewing and computer use on body mass index in young children. Arch Pediatr Adolesc Med 2008;162(3): 239-45.

31. Jago R, Sebire SJ, Gorely T, Cillero IH, Biddle SJ. "I'm on it 24/7 at the moment": a qualitative examination of multi-screen viewing behaviours among UK 10-11 year olds. Int J Behav Nutr Phys Act 2011; 8:85. 